\title{
BMJ Open Psychological impact of the COVID-19 pandemic within institutional quarantine and isolation centres and its sociodemographic correlates in Qatar: a cross-sectional study
}

Shuja Reagu (D) , ${ }^{1}$ Ovais Wadoo, ${ }^{1}$ Javed Latoo, ${ }^{1}$ Deborah Nelson, ${ }^{1}$ Sami Ouanes, ${ }^{1}$ Naseer Masoodi, ${ }^{2}$ Mustafa Abdul Karim (D) , ${ }^{1}$ Yousaf Iqbal, ${ }^{1}$ Samya Al Abdulla, ${ }^{3}$ Saleem Khaldoun Al Nuaimi, ${ }^{1}$ Alaaeldin Abdelmajid Basheer Abdelmajid, ${ }^{4}$ Musaed Saad Al samawi, ${ }^{4}$ Mohamed Adil Shah Khoodoruth, ${ }^{1}$ Widaad Nuzhah Chut-Kai Khoodoruth, ${ }^{4}$ Muna A Rahman S Al-Maslamani, ${ }^{4}$ Majid Alabdulla ${ }^{1,5}$

To cite: Reagu S, Wadoo 0, Latoo J, et al. Psychological impact of the COVID-19 pandemic within institutional quarantine and isolation centres and its sociodemographic correlates in Qatar: a crosssectional study. BMJ Open 2021;11:e045794. doi:10.1136/ bmjopen-2020-045794

- Prepublication history for this paper is available online. To view these files, please visit the journal online (http://dx.doi org/10.1136/bmjopen-2020045794).

Received 12 0ctober 2020 Revised 06 January 2021 Accepted 19 January 2021

Check for updates

(C) Author(s) (or their employer(s)) 2021. Re-use permitted under CC BY-NC. No commercial re-use. See rights and permissions. Published by BMJ.

For numbered affiliations see end of article.

Correspondence to

Dr Shuja Reagu;

sreagu@hamad.qa

\section{ABSTRACT}

Setting The State of Qatar has had one of the highest COVID-19 infection rates globally and has used statemanaged quarantine and isolation centres to limit the spread of infection. Quarantine and isolation have been shown to negatively affect the mental health of individuals. Qatar has a unique population, with around $90 \%$ of the population being economic migrants and a majority being blue-collar workers and labourers.

Objectives This study was carried out to evaluate the psychological impact of institutional isolation and quarantine during the COVID-19 pandemic outbreak in Qatar. The study also explored the sociodemographic correlates of this psychological impact.

Design, participants and intervention A crosssectional study involving 748 consenting individuals in institutional quarantine and isolation in Qatar during the months of June and July 2020 was carried out. Relevant sociodemographic data along with depressive and anxiety symptomatology scores were collected from consenting adults at these facilities.

Results $37.4 \%(n=270)$ of respondents reported depressive symptoms and $25.9 \%(n=189)$ reported anxiety symptoms. The scores were higher for individuals in isolation facilities and higher for migrants from poor socioeconomic group $(p<0.001$ for both). Within this group, although worries about infection were widely reported, lack of contact with the family was cited as one of the most important sources of distress. Respondents reported that contact with the family and reliable information were important factors that helped during the duration of isolation and quarantine.

Conclusions Our study reported significantly elevated scores for depression and anxiety during institutional quarantine, which is in keeping with emerging evidence. However, in contrast to other studies reporting mostly from native populations, this study of a population with an overwhelming majority of immigrants highlights the special mental health needs of this specific group and can inform future healthcare policies.
Strengths and limitations of this study

A large nationwide, cross-sectional study of adequate power.

- Use of validated tools for assessment of anxiety and depressive symptomatology.

- Studies previously unexplored area of psychological impact of institutional quarantine/isolation and related these to sociodemographic variables.

- Snapshot cross-sectional design does not allow for follow-up to explore the stability of the reported results.

Relies on self-reported symptoms.

\section{BACKGROUND}

COVID-19 was declared an international public health emergency on 30 January 2020 by the WHO. ${ }^{1}$ Isolation and quarantine of affected or suspected individuals were implemented on unprecedented large scales on populations across the globe to limit the spread of infection. ${ }^{2}$ By early April 2020, 90\% of the world's population was subject to some restriction of movement to limit the spread of infection. ${ }^{3}$ The nature and degree of quarantine during this public health emergency have not been uniform and have varied depending on the burden of infection, state responses and resources available to countries. The State of Qatar has been affected significantly by this pandemic. In fact, Qatar has had one of the highest numbers of COVID-19-positive patients per million population. ${ }^{45}$ The State of Qatar launched a nationwide public health strategy of institutional quarantine, resulting in the commissioning of 51 state-managed 
dedicated quarantine and isolation sites across the country beginning from 26 February 2020. People with confirmed infection were placed in hospital isolation centres. ${ }^{6}$ Individuals with exposure or suspected exposure to confirmed COVID-19 cases and all incoming travellers were placed in state-managed quarantine centres. ${ }^{6}$ These arrangements have since changed over time in response to the changing severity of the pandemic.

In Qatar, the public health sector plays a major role in healthcare provision in general and during the pandemic in particular. Both locals and migrants have ready access to heavily subsidised public healthcare facilities (primary healthcare centres and secondary and tertiary care hospitals).

Isolation and quarantine in times of epidemics have been known to have negative impacts on the psychosocial well-being. Studies have reported on the psychological impact of quarantine during previous infectious outbreaks. These studies have included people with SARS, Ebola, H1N1 influenza, Middle Eastern respiratory syndrome and equine influenza. ${ }^{7}$ General themes of psychological impact reported by these studies are fear of falling sick or dying, feelings of helplessness, increased levels of self-blame and depression. These have been well summarised by Brooks $e t a l^{7}$ who conclude that the psychological impact of quarantine is wide-ranging, substantial and can be long-lasting. Published studies exploring the psychological impact experienced during the current COVID-19 pandemic across the world report higher levels of depression, anxiety and post-traumatic symptoms in home-quarantined populations. ${ }^{8-12}$ Women and individuals aged between 18 and 30 years or older than 60 years have been reported to be more vulnerable to the psychological effects of quarantine. ${ }^{9} 1013$ However, these studies have not reported on individuals within institutional isolation facilities or within institutional quarantine facilities, which places individuals outside their home environments. Arguably, institutional quarantine may have contributed towards limiting the spread of infection, but it is qualitatively different from home and community-based quarantine.

Furthermore, researchers have attempted to explore factors that help to mitigate this mental health impact on quarantined populations. Here, physical activity, ${ }^{914}$ providing information ${ }^{915}$ and provision of adequate supplies ${ }^{16}$ to individuals in quarantine are some of the factors that have been noted to be helpful in coping with the psychological effects.

To our knowledge, therefore, ours is the first study that attempts to explore the mental health effects on individuals placed within institutional isolation and quarantine. Furthermore, we have reported on populations from the Middle East and North African region with its unique demographic and sociocultural context and high immigrant population. We aim to evaluate the characteristics of psychological impact and coping mechanisms in this specific population, which can inform mitigation strategies.

\section{Aims}

This study aimed to evaluate the psychological impact of institutional isolation and quarantine during the COVID-19 pandemic outbreak in Qatar. It also evaluated the correlation between psychological impact and clinical, demographic and socioeconomic characteristics of the quarantined population. A further aim was to explore measures that help reduce the burden of psychological impact of quarantine and isolation.

\section{MATERIALS AND METHODS}

The State of Qatar established dedicated government facilities as part of its pandemic response. In addition to designated hospital sites for treatment of patients with symptomatic COVID-19, there were government-run isolation centres that catered to the infected but asymptomatic individuals. Furthermore, there were designated hotel/hostel quarantine centres for suspected cases and those awaiting test results. Individuals in the isolation centres were transferred to the quarantine centres after the first negative result for infection, and they remained there till they tested negative a second time. The second test was carried out around a week after the first negative result. Individuals returning from overseas and those who were suspected of close high-risk contact with a confirmed positive case were also placed at the state quarantine centres. Again, the first negative result was followed by a second test a week later before quarantine was ended. The isolation centres were hospital-based, and individuals were placed in hospital wards with limited access to outside space and limited internet access. The quarantine centres were converted and catered hostel/hotel accommodations with limited communal areas/outside space, and most centres provided internet access.

We carried out a cross-sectional, nationwide study across the major quarantine and isolation centres established for the COVID-19 pandemic in Qatar starting from 1 June 2020 till 31 July 2020 with the following inclusion/ exclusion criteria for participation:

Inclusion criteria: consenting adults aged $\geq 18$ years, in quarantine or isolation due to the COVID-19 pandemic.

Exclusion criteria: inability to consent for participation in the study due to underlying mental health conditions or severe physical health symptoms due to COVID-19 infection; inability to engage with the written questionnaires due to illiteracy, learning difficulty or other.

\section{Sampling}

There were about 5000 individuals in COVID-19 quarantine and isolation at the start of April 2020 across 50 quarantine and isolation sites in Qatar. To calculate the required sample size, we used the prevalence of anxiety and depression symptoms (25\% and $28 \%$, respectively) during the COVID-19 outbreak in China as reported by Ren et al's meta-analysis. ${ }^{17}$ For a $95 \%$ CI and a margin of error of $3 \%$ of the estimated prevalence, the required sample size was $\mathrm{n}=735$. 
Table 1 Sociodemographic and clinical features of the studied sample

$$
\text { Ages, years, }
$$
mean $\pm S D$

\begin{tabular}{|c|c|c|}
\hline \multicolumn{2}{|l|}{ Sex, male, $\mathrm{n}(\%)$} & $388(51.9)$ \\
\hline \multirow[t]{7}{*}{ Nationality, n (\%) } & Qatari & $78(10.5)$ \\
\hline & Non-Qatari Arab & 88 (11.9) \\
\hline & Indian subcontinent & $260(35.0)$ \\
\hline & Southeast Asia & $144(19.4)$ \\
\hline & European & $42(5.7)$ \\
\hline & North American & $22(3.0)$ \\
\hline & Other & $108(14.5)$ \\
\hline \multirow[t]{3}{*}{ Occupation, n (\%) } & White collar & $456(61.0)$ \\
\hline & Labourer & $188(25.2)$ \\
\hline & Unemployed & $103(13.8)$ \\
\hline \multirow{3}{*}{$\begin{array}{l}\text { COVID-19 PCR test } \\
\text { result, } \mathrm{n}(\%)\end{array}$} & Negative & $269(40.1)$ \\
\hline & Positive & $394(58.8)$ \\
\hline & Inconclusive & $7(1.0)$ \\
\hline \multicolumn{2}{|c|}{ Duration of quarantine, days, mean $\pm S D$} & $7.0 \pm 4.9$ \\
\hline \multicolumn{2}{|c|}{ History of depression, n (\%) } & $21(2.8)$ \\
\hline \multicolumn{2}{|l|}{$\begin{array}{l}\text { History of anxiety, } \\
\mathrm{n}(\%)\end{array}$} & $43(5.7)$ \\
\hline \multicolumn{2}{|c|}{ History of psychosis, n (\%) } & $1(0.1)$ \\
\hline \multicolumn{2}{|c|}{$\begin{array}{l}\text { History of psychotropic medication intake, } \\
n(\%)\end{array}$} & $26(3.5)$ \\
\hline \multicolumn{2}{|c|}{ History of admission to psychiatry, n (\%) } & $17(2.3)$ \\
\hline \multicolumn{2}{|c|}{$\begin{array}{l}\text { History of psychotherapy/counselling, } n \\
(\%)\end{array}$} & $13(1.7)$ \\
\hline \multicolumn{2}{|c|}{ GAD-7 score, mean \pm SD } & $3.7 \pm 4.5$ \\
\hline \multicolumn{2}{|c|}{$\mathrm{PHQ}-9$ score, mean $\pm \mathrm{SD}$} & $4.6 \pm 5.0$ \\
\hline \multirow[t]{4}{*}{ Anxiety, n (\%) } & None & $549(74.1)$ \\
\hline & Mild & $123(16.6)$ \\
\hline & Moderate & $50(6.7)$ \\
\hline & Severe & $19(2.6)$ \\
\hline \multirow[t]{5}{*}{ Depression, n (\%) } & None & $460(62.6)$ \\
\hline & Mild & $153(20.8)$ \\
\hline & Moderate & $75(10.2)$ \\
\hline & Moderately severe & $38(5.2)$ \\
\hline & Severe & $9(1.2)$ \\
\hline
\end{tabular}

.GAD-7, seven-item Generalised Anxiety Disorder scale; PHQ-9, Patient Health Questionnaire nine-item depression scale.

The selection of participants was randomised using a system based on room number allocation (every fifth room number at larger facilities and alternate room numbers at smaller facilities).

\section{Patient and public involvement}

Patients or the public were not involved in the design or conduct of this research or in the dissemination of the research plans.
Survey and assessment of depressive and anxiety symptoms

A paper-based survey tool was used to collect data. The survey questionnaire included two sections. The first section was designed to collect data on demographic characteristics, duration of the quarantine, facilities and conditions in the facility, pre-existing mental health conditions, current or past use of mental health treatments (including medication) and COVID-19 infection testing status. The second section assessed depressive and anxiety symptoms using the Patient Health Questionnaire Anxiety-Depression Scale (PHQ-ADS), which is a validated and established self-administered tool combining the Patient Health Questionnaire nine-item depression scale (PHQ-9) and the seven-item Generalised Anxiety Disorder scale (GAD-7). ${ }^{18}$ The survey questionnaires were in English and Arabic, and the validated Arabic translation was used for PHQ-ADS. ${ }^{19}$

For PHQ-9, we used scores of 5, 10, 15 and 20 as cut-off points for mild, moderate, moderately severe and severe depression, respectively. ${ }^{20}$ For GAD-7, we used scores of 5, 10 and 15 as cut-off points for mild, moderate and severe anxiety, respectively. ${ }^{21}$ Calculation of prevalence rates for depressive symptoms included all PHQ-9 scores $\geq 5$ and for anxiety symptoms, all GAD-7 scores $\geq 5$.

\section{Statistical analysis}

Data were analysed using IBM SPSS Statistics for Windows V.25.0 (IBM).

For categorical variables, we calculated absolute and relative frequencies. For the prevalence of depression and anxiety, we also calculated 95\% CIs. For continuous variables, we calculated the mean and $\mathrm{SD}$. Whenever the variable did not follow the normal distribution, median and IQR were calculated.

To compare scores of depression and anxiety among categorical groups, we used t-test for independent samples whenever the size of each of the groups was at least 30. Otherwise, Mann-Whitney U test was used.

To examine the associations between depression and anxiety scores and continuous variables (age, duration of quarantine), we used Spearman's correlations (because none of these variables followed the normal distribution, as per the Shapiro-Wilk test).

We constructed multiple linear regression models (one with the PHQ-9 score as a dependent variable and the other with the GAD-7 score as a dependent variable) with age, sex, occupation (white collar vs labourer/unemployed), COVID-19 test result, duration of quarantine and psychiatric history (positive vs negative) as independent variables. For each of the linear regression models, the adjusted $\mathrm{R}^{2}$, the unstandardised $\mathrm{B}$ coefficient with its 95\% CI, the partial correlation coefficient $(r)$ and the $p$ value were calculated.

For all tests, the significance level was set at $\alpha=0.05$, and all tests were two-tailed. In case of multiple comparison, $\mathrm{p}$ values were adjusted using the Holm-Bonferroni method. 
Table 2 Sociodemographic and clinical factors associated with depression and anxiety symptoms

\begin{tabular}{|c|c|c|c|c|c|c|c|c|c|}
\hline & \multicolumn{2}{|l|}{ Gender } & \multirow[t]{2}{*}{$P$ value } & \multicolumn{2}{|l|}{ Occupation } & \multirow[t]{2}{*}{$P$ value } & \multicolumn{2}{|c|}{ COVID test result } & \multirow[t]{2}{*}{$P$ value } \\
\hline & Female & Male & & White collar & Labourer or unemployed & & Negative & Positive & \\
\hline GAD-7 score & 3.7 & 3.7 & 0.916 & 3.1 & 4.4 & $<0.001$ & 2.3 & 4.8 & $<0.001$ \\
\hline
\end{tabular}

$P$ values were adjusted for multiple comparison using the Holm-Bonferroni method.

GAD-7, seven-item Generalised Anxiety Disorder scale; PHQ-9, Patient Health Questionnaire nine-item depression scale.

\section{RESULTS}

\section{General characteristics and prevalence of depressive and} anxiety symptoms

Our sample consisted of 748 individuals, $51.9 \% \quad(n=388)$ of whom were men, with a median age of 36 years (IQR: 18; extremes of 18 and 94). More than half $(58.8 \%$, $\mathrm{n}=394$ ) had positive COVID-19 PCR results. The median duration of quarantine/isolation was 6 days (IQR: 7; extremes of 1 and 41).

The prevalence of depressive symptoms was $37.4 \%$ $(\mathrm{n}=270,95 \% \mathrm{CI}=33.7 \%$ to $41.1 \%)$. The prevalence of anxiety symptoms was $25.9 \%(\mathrm{n}=189,95 \% \mathrm{CI}=22.6 \%$ to $29.3 \%$ ). Table 1 summarises the main sociodemographic and clinical characteristics of the sample.

When asked what worried them most during quarantine, participants reported isolation $(40.4 \%, \mathrm{n}=302)$, infection $(39.4 \%, \mathrm{n}=295)$, family health $(32.9 \%, \mathrm{n}=246)$ and finances $(32.5 \%, \mathrm{n}=243)$. Among things that helped them the most during quarantine, participants reported talking to family $(54.0 \%, \mathrm{n}=404)$, internet $(38.9 \%$, $\mathrm{n}=291)$, information $(31.2 \%, \mathrm{n}=233)$, exercise $(23.8 \%$, $\mathrm{n}=178)$, reading $(22.2 \%, \mathrm{n}=166)$ and access to outside world $(12.8 \%, \mathrm{n}=96)$.

\section{Factors associated with depression and anxiety (univariate analysis)}

Tables 2 and 3 show the associations between the categorical sociodemographic and clinical factors and depressive and anxiety symptoms. Men had higher PHQ-9 scores than women ( 5.0 vs $4.1 ; \mathrm{p}=0.034$ ), but no difference was found between genders in anxiety scores. No link was found between age and depressive or anxiety symptoms.

Labourers and unemployed participants exhibited more pronounced depressive (6.1 vs 3.7; $\mathrm{p}<0.001)$ and anxiety symptoms $(4.4$ vs $3.1 ; \mathrm{p}<0.001)$ than white-collar participants.
In addition, participants with positive PCR COVID-19 tests had significantly higher levels of depressive (6.1 vs $2.8 ; \mathrm{p}<0.001)$ and anxiety (4.8 vs $2.3 ; \mathrm{p}<0.001)$ symptoms than participants with negative tests. We also found negative weak correlations between the duration in quarantine, and PHQ-9 and GAD-7 scores (rho=-0.083, $\mathrm{p}=0.029$ and rho $=-0.101, \mathrm{p}=0.008$, respectively).

A history of depression, a history of anxiety and a history of admission to psychiatry were associated with higher PHQ-9 and GAD-7 scores (table 3).

In addition, a strong positive correlation was noted between depression and anxiety scores (rho=0.760, $\mathrm{p}<0.001)$.

GAD-7 score was significantly higher in participants who said they were particularly worried about infection or about their family's health, whereas PHQ-9 score was significantly higher in participants who said they were mostly worried about isolation or about their family's health (table 4). GAD-7 and PHQ-9 scores were significantly lower in individuals who reported the most helpful thing during quarantine to be access to internet, reading or exercise, but not in those who said the most helpful thing was going outside, talking to the family or having been provided with information (table 5).

\section{Multiple linear regression analysis}

In multiple regression analysis, higher GAD-7 scores were significantly linked to female gender $(B=-0.885(-1.710$ to -0.061$) ; \mathrm{p}=0.035, \mathrm{r}=-0.91)$, a positive COVID-19 PCR result $(\mathrm{B}=2.387$ (1.492 to 3.282$) ; \mathrm{p}<0.001, \mathrm{r}=0.222)$, the presence of a positive psychiatric history $(\mathrm{B}=4.115$ (2.655 to 5.576); $\mathrm{p}<0.001, \mathrm{r}=0.234)$ and a lower duration of quarantine $(\mathrm{B}=-0.103(-0.177$ to -0.028$) ; \mathrm{p}=0.007, \mathrm{r}=-0.117)$, but not with age. The adjusted $\mathrm{R}^{2}$ was 0.133 (table 6 ).

Higher PHQ-9 scores were significantly linked to a positive COVID-19 PCR result ( $\mathrm{B}=2.904$ (1.905 to 3.904);

Table 3 Associations between psychiatric history and depression and anxiety symptoms

\begin{tabular}{|c|c|c|c|c|c|c|c|c|c|}
\hline & \multicolumn{2}{|c|}{ History of depression } & $P$ value & \multicolumn{2}{|c|}{ History of anxiety } & \multirow[t]{2}{*}{$P$ value } & \multicolumn{2}{|c|}{$\begin{array}{l}\text { History of admission to } \\
\text { psychiatry }\end{array}$} & \multirow[t]{2}{*}{$P$ value } \\
\hline & No & Yes & & No & Yes & & No & Yes & \\
\hline PHQ-9 score & 4.4 & 12.5 & $<0.001$ & 4.3 & 9.3 & $<0.001$ & 4.4 & 10.3 & $<0.001$ \\
\hline
\end{tabular}

$P$ values were adjusted for multiple comparison using the Holm-Bonferroni method.

GAD-7, seven-item Generalised Anxiety Disorder scale; PHQ-9, Patient Health Questionnaire nine-item depression scale. 
Table 4 Associations between the most important worries reported during quarantine and depression and anxiety symptoms

\begin{tabular}{|c|c|c|c|c|c|c|c|c|c|c|c|c|c|c|c|}
\hline & \multicolumn{2}{|c|}{$\begin{array}{l}\text { Worried } \\
\text { about } \\
\text { isolation }\end{array}$} & $\begin{array}{l}P \\
\text { value }\end{array}$ & \multicolumn{2}{|c|}{$\begin{array}{l}\text { Worried } \\
\text { about } \\
\text { infection }\end{array}$} & $\begin{array}{l}P \\
\text { value }\end{array}$ & \multicolumn{2}{|c|}{$\begin{array}{l}\text { Worried } \\
\text { about } \\
\text { family } \\
\text { health }\end{array}$} & $\mathrm{P}$ value & \multicolumn{2}{|c|}{$\begin{array}{l}\text { Worried } \\
\text { about } \\
\text { finances }\end{array}$} & $\begin{array}{l}P \\
\text { value }\end{array}$ & \multicolumn{2}{|c|}{$\begin{array}{l}\text { Worried } \\
\text { about } \\
\text { getting } \\
\text { food }\end{array}$} & $\begin{array}{l}P \\
\text { value }\end{array}$ \\
\hline GAD-7 score & 3.4 & 4.2 & 0.072 & 3.3 & 4.3 & 0.016 & 3.2 & 4.9 & $<0.001$ & 3.6 & 4.0 & 0.209 & 3.6 & 5.0 & 0.208 \\
\hline PHQ-9 score & 4.2 & 5.2 & 0.024 & 4.3 & 5.1 & 0.120 & 4.0 & 5.7 & $<0.001$ & 4.5 & 4.7 & 0.578 & 4.5 & 6.1 & 0.136 \\
\hline
\end{tabular}

$P$ values were adjusted for multiple comparison using the Holm-Bonferroni method.

GAD-7, seven-item Generalised Anxiety Disorder scale; PHQ-9, Patient Health Questionnaire nine-item depression scale.

$\mathrm{p}<0.001, \mathrm{r}=0.241)$, the presence of a positive psychiatric history ( $\mathrm{B}=4.731$ (3.099 to 6.362); $\mathrm{p}<0.001, \mathrm{r}=0.241)$ and a lower duration of quarantine $(\mathrm{B}=-0.106 \quad(-0.189$ to $-0.024) ; \mathrm{p}=0.012, \mathrm{r}=-0.109)$, but not with age or sex. The adjusted $R^{2}$ was 0.163 (table 7 ).

\section{DISCUSSION}

To our knowledge, this is the first study of its kind that explores a nationwide sample from state-managed institutional isolation and quarantine centres and one that explores immigrant mental health in the context of this pandemic.

The main finding of the study was high levels of anxiety and depressive symptoms among individuals placed within state-managed isolation and quarantine centres.

As many as $37.4 \%$ of the respondents in our study reported depressive symptoms, with nearly half of these approaching scores of moderate to severe depression. Around $26 \%$ of the respondents reported anxiety symptoms, and almost a third among these had moderate to severe anxiety. These rates are significantly higher than the self-reported history of depression and anxiety, by this study population, which were in the region of $3 \%$ and $6 \%$, respectively. Furthermore, these are higher rates even when compared with the prepandemic prevalence rates of depression and anxiety in Qatar, which are 13.8\% and $12.1 \%$, respectively. ${ }^{22}$ Evidence of the psychological impact of quarantine for COVID-19 is still emerging, and when compared with the few other studies on quarantined populations, ${ }^{8-12}$ the rates and severity of anxiety and depression in this study were towards the higher side. Paz et at in their study on a home-quarantined population in Ecuador used the same instruments as that in this study on a similar sample size and reported comparable rates of moderate to severe anxiety and depression. An Irish study on home-quarantined population reported anxiety rates of $20 \%$ and depression rates of $22.8 \%$ also using the same instruments as those in this study. ${ }^{10}$ Studies from China looking at depression and anxiety rates among home-quarantined populations using self-rating scales have reported anxiety rates ranging from $6.2 \%$ to $12.9 \%$ and depression rates of up to $22.4 \% .^{811} 12$ This study's high rates could be because the other studies examined individuals in home and community-based quarantine, whereas our study looked at institutional quarantine where individuals are removed from their home environments. These rates could have been further influenced by the unique sociodemographic composition of the study population as we discuss below.

Respondents who were unemployed, had lost their jobs or were in low-paid jobs reported significantly higher scores for both depression and anxiety. Nearly $40 \%$ of the respondents cited social isolation as their biggest source of distress, followed closely by fear of the COVID-19 disease itself and then financial worries. More than half of the respondents reported that it was contact with their family and friends that provided the biggest source of coping with their quarantine. This can be better understood by placing these findings within the sociodemographic context of Qatar. Qatar's population is somewhat unique in that the majority of the population (up to $88 \%$ ) comprise foreign nationals who are working in

Table 5 Associations between coping tools deemed most helpful to reduce the psychological distress in quarantine and depression and anxiety symptoms

\begin{tabular}{|c|c|c|c|c|c|c|c|c|c|c|c|c|c|c|c|c|c|c|}
\hline & \multicolumn{2}{|c|}{$\begin{array}{l}\text { Taking to } \\
\text { family }\end{array}$} & \multirow[t]{2}{*}{$\begin{array}{l}P \\
\text { value }\end{array}$} & \multicolumn{2}{|c|}{ Internet } & \multirow[t]{2}{*}{$\begin{array}{l}P \\
\text { value }\end{array}$} & \multicolumn{2}{|c|}{ Information } & \multirow[t]{2}{*}{$P$ value } & \multicolumn{2}{|c|}{ Exercise } & \multirow[t]{2}{*}{$\begin{array}{l}P \\
\text { value }\end{array}$} & \multicolumn{2}{|c|}{ Reading } & \multirow[t]{2}{*}{$\begin{array}{l}P \\
\text { value }\end{array}$} & \multicolumn{2}{|c|}{$\begin{array}{l}\text { Access to } \\
\text { outside } \\
\text { world }\end{array}$} & \multirow[t]{2}{*}{$\begin{array}{l}P \\
\text { value }\end{array}$} \\
\hline & No & Yes & & No & Yes & & No & Yes & & No & Yes & & No & Yes & & No & Yes & \\
\hline $\begin{array}{l}\text { PHQ-9 } \\
\text { score }\end{array}$ & 4.9 & 4.3 & 0.288 & 5.1 & 3.7 & 0.001 & 4.6 & 4.6 & 0.973 & 4.9 & 3.6 & 0.001 & 5.0 & 3.2 & 0.001 & 4.5 & 5.1 & 0.522 \\
\hline
\end{tabular}

$P$ values were adjusted for multiple comparison using the Holm-Bonferroni method.

GAD-7, seven-item Generalised Anxiety Disorder scale; PHQ-9, Patient Health Questionnaire nine-item depression scale. 
Table 6 Variables associated with anxiety symptoms - multiple linear regression analysis

$95 \% \mathrm{Cl}$ for B

\begin{tabular}{llllcr} 
Variable & B & P value & Lower bound & Upper bound & Partial correlation coefficient \\
\hline Age & -0.010 & 0.561 & -0.044 & 0.024 & -0.025 \\
Gender & -0.885 & 0.035 & -1.710 & -0.061 & -0.091 \\
Occupation & -0.375 & 0.433 & -1.314 & 0.565 & -0.034 \\
COVID-19 test result & 2.387 & 0.000 & 1.492 & 3.282 & 0.222 \\
Duration of quarantine & -0.103 & 0.007 & -0.177 & -0.028 & -0.117 \\
Psychiatric history & 4.115 & 0.000 & 2.655 & 5.576 & 0.234 \\
\hline
\end{tabular}

this small Arabian Gulf country. ${ }^{23}$ This foreign workforce comprises predominantly young men and economically active group who have families in their home countries. A significant majority work as manual labourers as the State of Qatar continues to grow economically and in infrastructure. ${ }^{24}$ The results therefore are influenced by the anxieties and distress faced by this group who could not establish contact with their families while placed in isolation and quarantine facilities and had limited means to achieve and establish this contact. For various reasons, many of them did not have smartphones or tablets at their disposal to communicate with their families. The other major concerns for this group are perhaps, expectedly, those related to finance and job security.

Interestingly, in this study, higher GAD-7 and PHQ-9 scores were linked with shorter duration of quarantine. We believe a potential explanation could be that individuals were likely to be much more anxious and distressed in the initial period when they had just moved to these restrictive facilities and had just been tested or had tested positive for the SARS-CoV-2 infection. Although the high scores continued during the entirety of the quarantine, there was some degree of adaptation and reconciling with the restrictive facilities as the time progressed.

It is well established that migrant workers form a susceptible group when it comes to mental health stress and availability of coping mechanisms. ${ }^{25}$ Preliminary reports note evolving mental health crises among migrants in Lebanon and India in the context of COVID-19 and economic downturn. ${ }^{2627}$ These groups also reported high rates of anxiety and depression. However, while migrant groups in India and Lebanon reported poor access to healthcare as the main cause of distress, the group in Qatar had access to free, state-provided healthcare, and their main source of distress was social isolation.

The subgroup of individuals in the isolation centres who were positive for SARS-CoV-2 infection reported significantly higher scores for both depression and anxiety. This could be explained by the fact that the hospital isolation facilities allowed even more limited social interaction and almost no access to outside world. The fear of the disease itself and paucity of information are more pronounced in the isolation facilities when compared with quarantine facilities. Following social support, the next biggest reported category of helpful measures was access to reliable information about the disease and factors related to quarantine. There is evidence that provision of reliable information and communication can mitigate the negative psychological impacts of quarantine. ${ }^{9} 1415$ These findings may be used to inform healthcare planning in the context of institutional quarantine and in migrant populations.

\section{Strengths and limitations}

The strengths of this study lie in the fact that it was nationwide, adequately powered and explored yet unchartered areas of mental health repercussions of the COVID-19 pandemic on individuals in institutional quarantine and related these to sociodemographic variables. Validated tools were used to assess anxiety and depressive symptomatology. The limitations of our study include a crosssectional design that did not provide for follow-up, so the stability of the reported symptoms was not explored. In addition, a self-report measure was used to collect the

Table 7 Variables associated with depressive symptoms - multiple linear regression analysis

\section{5\% Cl for B}

\begin{tabular}{lrlccr} 
Variable & B & P value & Lower bound & Upper bound & Partial correlation coefficient \\
Age & -0.026 & 0.196 & -0.064 & 0.013 & -0.056 \\
Gender & -0.417 & 0.377 & -1.343 & 0.509 & -0.038 \\
Occupation & 0.222 & 0.680 & -0.832 & 1.276 & 0.018 \\
COVID-19 test result & 2.904 & 0.000 & 1.905 & 3.904 & 0.241 \\
Duration of quarantine & -0.106 & 0.012 & -0.189 & -0.024 & -0.109 \\
Psychiatric history & 4.731 & 0.000 & 3.099 & 6.362 & 0.241 \\
\hline
\end{tabular}


data. Due to practical considerations, patients with severe illness had to be excluded.

The data set was somewhat self-selecting as only those who gave consent were included.

\section{CONCLUSION AND IMPLICATIONS}

This worldwide public health emergency has had a significant impact on the mental health of entire populations and not just those infected with the virus. While the pandemic has affected individuals physically when they were infected, it appears that the mental health effects have been far more widespread. ${ }^{28-30}$ This is likely to pose a significant burden for stretched and chronically underresourced mental health services, ${ }^{31}$ and we may very well see a mental health epidemic closely following on the heels of this pandemic. Although Qatar has had relatively low mortality and physical morbidity from the COVID-19 pandemic, it has not escaped the mental health impact. In a way, Qatar's apparent advantage of having a young, active population that even when exposed to very high levels of infection escaped physical health morbidity has exposed it to a significantly increased mental health burden as this group had limited means to access social support from family and friends which has been proven to be effective. ${ }^{24}$ The importance of these results may not be limited to this region and can potentially be significant in a world which is seeing rising numbers of immigrant populations-individuals who are reliant on communication and travel and for whom financial uncertainties can be more damning.

The results of this study suggest that in managing this and future health emergencies, healthcare planning should incorporate screening for mental health issues in vulnerable groups such as migrant populations, and consideration should be given to maintaining social support channels and provision of appropriate and reliable information.

\section{Author affiliations}

${ }^{1}$ Psychiatry, Hamad Medical Corporation, Doha, Qatar

${ }^{2}$ Medicine, Hamad Medical Corporation, Doha, Qatar

${ }^{3}$ Primary Health Care Corporation, Doha, Ad Dawhah, Qatar

${ }^{4}$ Communicable Disease Center, Doha, Qatar

${ }^{5}$ Psychiatry, College of Medicine, Qatar University, Doha, Qatar

Contributors SMR, DN, JAL and MAA conceptualised the study. SMR, SAA, S.K.N and M.R.M. contributed to the design and planning of the study. SMR and OW wrote the manuscript. SMR, NAM, MAK, JAL, YI, ABA, MSS, SO, MASK, OW and WNK helped in data acquisition and data management. SO and SMR analysed the data. All authors contributed in the review and revision of the manuscript.

Funding The authors have not declared a specific grant for this research from any funding agency in the public, commercial or not-for-profit sectors.

Competing interests None declared.

Patient and public involvement Patients and/or the public were not involved in the design, or conduct, or reporting, or dissemination plans of this research.

Patient consent for publication Not required.

Ethics approval The study was approved by Hamad Medical Corporation Institutional Review Board (ref. MRC-05-086). An information sheet was provided to all the participants, which included details to access mental health help if needed. Written informed consent was obtained from all the participants.

Provenance and peer review Not commissioned; externally peer reviewed.

Data availability statement All data relevant to the study are included in the article or uploaded as supplementary information. The data that support the findings of this study are available from the corresponding author upon reasonable request and pending additional ethical approval.

Open access This is an open access article distributed in accordance with the Creative Commons Attribution Non Commercial (CC BY-NC 4.0) license, which permits others to distribute, remix, adapt, build upon this work non-commercially, and license their derivative works on different terms, provided the original work is properly cited, appropriate credit is given, any changes made indicated, and the use is non-commercial. See: http://creativecommons.org/licenses/by-nc/4.0/.

\section{ORCID iDs}

Shuja Reagu http://orcid.org/0000-0003-0801-4653

Mustafa Abdul Karim http://orcid.org/0000-0003-0497-1528

\section{REFERENCES}

1 World Health Organization,. Available: https://www.who.int/ emergencies/diseases/novel-coronavirus-2019/interactive-timeline\# category-Information [Accessed August 2020].

2 Centers for Disease Control and Prevention. Quarantine and isolation.. Available: https://www.cdc.gov/quarantine/index.html

3 . Available: https://www.pewresearch.org/fact-tank/2020/04/01/ more-than-nine-in-ten-people-worldwide-live-in-countries-withtravel-restrictions-amid-covid-19/ [Accessed August 2020].

4 Raddad LJA, Chemaitelly $\mathrm{H}$, Ayoub HH. Characterizing the Qatar advanced-phase SARS-CoV-2 epidemic. medRxiv. [Epub ahead of print: July 19, 2020].

5 Wordometer. COVID-19 coronavirus pandemic. Wordometer, 2020. Available: https:// www.worldometers.info/coronavirus/?utm campaign=homeAdUOA?Si [Accessed August 2020].

6 Wadoo O, Latoo J, Reagu SM, et al. Mental health during COVID-19 in Qatar. General Psychiatry 2020;33:e100313.

7 Brooks SK, Webster RK, Smith LE, et al. The psychological impact of quarantine and how to reduce it: rapid review of the evidence. The Lancet 2020;395:912-20.

8 Guo Y, Cheng C, Zeng Y, et al. Mental health disorders and associated risk factors in Quarantined adults during the COVID-19 outbreak in China: cross-sectional study. J Med Internet Res 2020;22:e20328.

9 Paz C, Mascialino G, Adana-Díaz L, et al. Behavioral and sociodemographic predictors of anxiety and depression in patients under epidemiological surveillance for COVID-19 in Ecuador. PLoS One 2020;15:e0240008.

10 Hyland P, Shevlin M, McBride O, et al. Anxiety and depression in the Republic of Ireland during the COVID-19 pandemic. Acta Psychiatr Scand 2020;142:249-56.

11 Lei L, Huang X, Zhang S. Comparison of prevalence and associated factors of anxiety and depression among people affected by versus people unaffected by quarantine during the COVID-19 epidemic in southwestern China. Medical Science Monitor: International Medical Journal of Experimental and Clinical Research, 2020: 26. e924609-1.

12 Gao J, Zheng P, Jia Y, et al. Mental health problems and social media exposure during COVID-19 outbreak. PLoS One 2020;15:e0231924.

13 Qiu J, Shen B, Zhao M. A nationwide survey of psychological distress among Chinese people in the COVID-19 epidemic: implications and policy recommendations [published correction appears in Gen Psychiatr. 2020 Apr 27;33(2):e100213corr1]. Gen Psychiatr 2020;33:e100213.

14 Chtourou $\mathrm{H}$, Trabelsi $\mathrm{K}, \mathrm{H}$ 'mida $\mathrm{C}$, et al. Staying physically active during the quarantine and self-isolation period for controlling and mitigating the COVID-19 pandemic: a systematic overview of the literature. Front Psychol 2020;11.

15 Imran N, Aamer I, Sharif MI, et al. Psychological burden of quarantine in children and adolescents: a rapid systematic review and proposed solutions. Pak J Med Sci 2020;36:1106.

16 Manuell M-E, Cukor J. Mother nature versus human nature: public compliance with evacuation and quarantine. Disasters 2011;35:417-42.

17 Ren X, Huang W, Pan H, et al. Mental health during the Covid-19 outbreak in China: a meta-analysis. Psychiatr Q 2020;91:1033-45.

18 Kroenke K, Wu J, Yu Z. Patient health questionnaire anxiety and depression scale: initial validation in three clinical trials. Psychosom Med 2016;78:716-27. 
19 Sawaya $\mathrm{H}$, Atoui M, Hamadeh A, et al. Adaptation and initial validation of the Patient Health Questionnaire - 9 (PHQ-9) and the Generalized Anxiety Disorder - 7 Questionnaire (GAD-7) in an Arabic speaking Lebanese psychiatric outpatient sample. Psychiatry Res 2016;239:245-52.

20 Kroenke K, Spitzer RL, Williams JB. The PHQ-9: validity of a brief depression severity measure. J Gen Intern Med 2001;16:606-13.

21 Spitzer RL, Kroenke K, Williams JBW, et al. A brief measure for assessing generalized anxiety disorder. Arch Intern Med 2006;166:1092-7.

22 Bener A, Abou-Saleh M, Dafeeah E, et al. The prevalence and burden of psychiatric disorders in primary health care visits in Qatar: too little time? Journal of Family Medicine and Primary Care 2015;4:89.

23 Available: https://www.psa.gov.qa/en/statistics/Statistical\% 20Releases/Population/Population/2020/Population_Social_ Statistics_Q2.pdf

24 . Available: https://www.psa.gov.qa/en/statistics/Statistical\% 20Releases/Social/LaborForce/2017/statistical_analysis_labor_force 2017_En.pdf [Accessed August 2020].
25 Bhugra D. Migration and mental health. Acta Psychiatr Scand 2004;109:243-58.

26 . Available: https://www.msf.org/covid-19-and-economic-downfallreveal-mental-health-crisis-lebanon [Accessed August 2020]

27 Kumar K, Mehra A, Sahoo S, et al. The psychological impact of COVID-19 pandemic and lockdown on the migrant workers: a crosssectional survey. Asian J Psychiatr 2020;53:102252.

28 Mazza C, Ricci E, Biondi S, et al. A nationwide survey of psychological distress among Italian people during the COVID-19 pandemic: immediate psychological responses and associated factors. Int J Environ Res Public Health 2020;17:3165.

29 Shigemura J, Ursano RJ, Morganstein JC, et al. Public responses to the novel 2019 coronavirus (2019-nCoV) in Japan: mental health consequences and target populations. Psychiatry Clin Neurosci 2020;74:281-2.

30 Lai J, Ma S, Wang Y, et al. Factors associated with mental health outcomes among health care workers exposed to coronavirus disease 2019. JAMA Netw Open 2020;3:e203976.

31 Pernice-Duca F. Family network support and mental health recovery. J Marital Fam Ther 2010;36:13-27. 